\title{
Discrete ex situ and Continuous in situ Real-Time Respiration Rate Measurements of Fresh Produce using a Novel Automated Dynamic Approach
}

\author{
Emma R. Collings, M. Carmen Alamar, Katherine Cools, José Juan Ordaz-Ortiz ${ }^{1}$ and Leon A. Terrya \\ Plant Science Laboratory, Cranfield University, Bedfordshire, MK43 OAL, United Kingdom.
}

1Present address: National Laboratory of Genomics for Biodiversity, CINVESTAV IPN, 36821, Irapuato, Guanajuato, Mexico.

\begin{abstract}
Fresh produce respiration rate is a useful indicator of metabolic state often used in postharvest research to determine physiological differences between factors. Static (no flow) and dynamic (constant flow) measurements are two types of methods that exist for determining respiration rate in fresh produce. Implementation of an automated real-time respiration method, using a dynamic measurement, for measuring respiration rates of fresh produce in discrete (ex situ) and continuous (in situ) set-ups has been established. Discrete methods were performed on fresh (green) black pepper within $3 \mathrm{~L}$ hermetically sealed containers with constant flow rates of $400 \mathrm{~mL} \mathrm{min-1}$ and $1 \mathrm{~L}$ min-1, respectively. Continuous respiration measurements were also obtained in situ for fresh black pepper stored under air $\left(1.8 \mathrm{~L} \mathrm{~min}^{-1}\right)$ at $5^{\circ} \mathrm{C}$, and avocado fruit stored under air and controlled atmosphere environment (ca. $10 \mathrm{kPa} \mathrm{CO}$ and $10 \mathrm{kPa} \mathrm{O}_{2} ; 400 \mathrm{~mL} \mathrm{~min}^{-1}$ ), at $20^{\circ} \mathrm{C}$. In addition, simultaneous automated recordings of $\mathrm{O}_{2}$ and $\mathrm{CO}_{2}$ enabled accurate respiratory quotient (RQ) values to be determined for avocado throughout storage. Application of the continuous dynamic in situ measurements can also provide a more realistic assessment of physiological change / behaviour under realworld storage conditions. In this paper, we discuss the application of both discrete and continuous dynamic methods as powerful research techniques for measuring respiration rate in postharvest research.
\end{abstract}

Keywords: Sable Respirometry System, Respiratory Quotient, Piper nigrum, Persea americana

\section{INTRODUCTION}

Aerobic respiration involves the oxidative catabolism of carbohydrate, protein and organic acid reserves into simpler molecules including $\mathrm{CO}_{2}$ and water which releases energy for plant biochemical processes. This process also consumes oxygen for various enzymatic reactions/pathways including glycolysis, the tricarboxylic acid cycle and the electron transport system. Depending on the metabolic substrate used, the typical ratio of $\mathrm{CO}_{2}$ produced to $\mathrm{O}_{2}$ consumed (respiratory quotient [RQ]) can range from 0.7 to 1.3 (Fonseca et al., 2002). Automated methods which can simultaneously measure $\mathrm{O}_{2}$ and $\mathrm{CO}_{2}$ can provide additional information regarding metabolic activity in various fresh commodities.

Techniques widely used for measuring respiration rate typically involve either a static or dynamic system (Downes et al., 2010; Cools et al., 2014; Saquet et al., 2003; Gapper et al., 2006), which are differentiated based on the absence or presence of air circulation, respectively. Disadvantages of a static system include susceptibility to leaks, and for climacteric fruit, a build-up of $\mathrm{CO}_{2}$ and depletion of $\mathrm{O}_{2}$ could eventually result in a modified atmosphere potentially altering respiration rate, thus generating false results. This is particularly important for produce which are removed from a controlled atmosphere (CA) environment prior to analysis, since there could be an efflux of gases which could build-up inside a static container if a suitable equilibration time has not been chosen. If samples are measured in situ, this would not be an issue. However, if fruit are removed, produce can a Email: l.a.terry@cranfield.ac.uk 
be placed directly in a dynamic system, and continuous measurements will accurately determine when produce have reached a stable equilibrium without exposure to a modified atmosphere from CA gas efflux.

As with static system, dynamic or flow-through respirometry methods are also susceptible to leaks, however, leaks can be easily detected since flow rate is continuously monitored and recorded. In addition, since the atmosphere inside the containers is continuously replaced, stress from built up modified atmosphere is avoided. Previous literature has reported the use of dynamic systems for measuring respiration rate such as Saquet et al. (2003) and Gapper et al. (2006), while automated measurements were described early on in Watada et al. (1981) and more recently in Calegario et al. (2001). Nevertheless, these methods did not measure in situ respiration rate.

Dynamic systems, which can measure both incurrent and excurrent gas concentrations, also offer the potential for measuring in situ respiration rate of produce under different CA conditions. Guo et al. (2013) used a dynamic system to measure the respiration rate of broccoli samples which were initially stored under $\mathrm{CA}$ atmosphere; however, samples were removed from storage and required equilibration for $8 \mathrm{~h}$ at $15^{\circ} \mathrm{C}$ before being placed in sealed containers for respiration rate assessment. In contrast, in situ analysis allows the commodity to remain undisturbed and avoids the necessity to equilibrate samples after removal from CA storage due to change in temperature and or gaseous environment. Equilibration time, which can be product specific, may actually affect the physiological response of fresh produce. Thus, using a continuous in situ method avoids the necessity to perform trial experiments to assess/confirm the equilibration time required for each commodity. Various other studies have measured respiration rate directly from the storage environment, yet these were not automated. Barrios et al. (2014) stored strawberry fruit under CA but in a closed system to simulate packaging, thus making automated analysis difficult. Continuous flow measurements of sugarcane stalks stored under CA were performed by Frateschi et al. (2013); yet, gas flow into the boxes had to be interrupted for 60s to obtain gas samples for analysis by manual GC injection. In a more recent study, real-time respiration rate, RQ and low oxygen limit (LOL) were measured using a sensor-based respiromter for carrot (in situ) whilst stored under CA (low $\mathrm{O}_{2}$ ). However, as with the other studies, gas flow was interrupted for $4 \mathrm{~h}$ to acquire these measurements (Mahajan et al., 2016). Despite the importance of $\mathrm{RQ}$ in determining metabolic state, additional work reporting real-time $\mathrm{RQ}$ measurements prior to this study are scant. Previous literature demonstrating continuous in situ storage for measuring respiration rate has only been performed using custom built dynamic hyperbaric respirometers (Goyette et al., 2012; Liplap et al., 2014).

Alternative commercial set-ups without hyperbaric conditions, such as the Sable System, are based on the dynamic approach and can measure $\mathrm{CO}_{2}$ production and $\mathrm{O}_{2}$ consumption simultaneously (as previously described in Collings et al., 2013). Previous research using the Sable Respirometry System has mainly focused on measuring respiration rate in insects and humans (Lighton and Schilman, 2007; Melanson et al., 2010). In this paper, we demonstrate the application of using this flow-through system for measuring respiration rate in fresh produce. In particular, highlighting and demonstrating the ability of using the system to determine respiration whilst produce remain within a constant controlled atmosphere environment, which has not previously been described in literature.

\section{MATERIALS AND METHODS}

Discrete (ex situ) respiration rate measurements, involving produce removal from storage and placement within hermetically sealed containers with constant flow, was performed on fresh (green) black pepper; whereas continuous (in situ) measurements were recorded for fresh black pepper (stored in air) and avocado (stored in air and CA conditions) whilst remaining in storage under dynamic conditions.

\section{Fruit material and sample preparation}

In 2014, fresh black pepper (Piper nigrum L. cv. Sri Lanka) sourced from Somsak Suksum (Thamai District, Chanthaburi province, Thailand) was harvested on 23 June (late season), and received at Cranfield University, UK (CU) on 30 June. After harvest, samples were transported for 4 
hours by non-refrigerated truck before being re-packaged into a polystyrene box lined with perforated plastic and gel ice packs. Total number of days required for transportation (from harvest to arrival at CU) was seven days.

Avocado (Persea americana L. cv. Hass) were grown at Fairview Farm near Tzaneen, South Africa and packed at Bassan. The avocados were transported from South Africa on 19 May 2013 under high nitrogen conditions at ca. $7^{\circ} \mathrm{C}$, and arrived at Tilbury Docks (Essex) on 6 June 2013. The fruit were transported from Worldwide Fruit (Spalding, Lincs., UK) to CU on 10 June 2013 and immediately transferred to the treatment boxes.

\section{Real-time respiration rate measurements}

Gas samples were analysed using a Sable Respirometry System (Model 1.3.8 Pro, Sable Systems International, NV, USA) as described in Collings et al. (2013) with slight modifications. A 'push mode' set up was used where air was passed to the system using either a basic air pump (jars) or directly from storage boxes using either a blower manifold or CA set-up. Automated switching between each sample jar/box was performed using the MUX flow multiplexer, which also recorded incurrent flow rate (FR [mL min-1]). As water vapour pressure was determined using a RH-300 water vapour detector, the sampled air did not require drying prior to entering the CA-10 carbon dioxide (firmware version 1.05) detector or FC-10 oxygen detector (firmware version 3.0). The carbon dioxide detector consisted of a dual wavelength infrared emitter which has a resolution of $1 \mu \mathrm{L} \mathrm{L}^{-1}$, while the oxygen detector contained 'fuel cell' oxygen sensors capable of obtaining a resolution of $0.0001 \%$. Barometric pressure (BP [kPa]) was also recorded with the CA-10 carbon dioxide detector. In all experimental analysis, baseline measurements consisting of an empty jar/box were recorded in between sample measurements to prevent cross contamination and to allow initial $\mathrm{O}_{2}$ and $\mathrm{CO}_{2}$ levels (including particular CA conditions) to be accurately determined. These baseline values were later subtracted from sample measurements to accurately determine respiration rate. For discrete respiration rate measurements, a minimum of 3 cycles per sample jar/box were recorded to obtain an average value. Software calculations were performed as described previously in Collings et al. (2013). However, for the experimental set-ups using different CA conditions, multiple baseline markers were required to accurately adjust respiration rate calculations.

\section{Discrete respiration rate measurements}

Upon arrival at $\mathrm{CU}$, individual fresh black pepper rachis $(\mathrm{n}=32)$ were weighed and placed inside each $13 \mathrm{~L}$ box $(\mathrm{n}=3)$ and stored at $5^{\circ} \mathrm{C}$. All $13 \mathrm{~L}$ storage boxes were constantly flushed with air (1.8 L min-1) from inside the cool room using a blower SLL40 (40 L min-1 flow rate capacity) manifold with flow regulator (custom built and supplied by Air Equipment, Beds., UK) to prevent accumulation of carbon dioxide $\left(\mathrm{CO}_{2}\right)$ and ethylene inside the boxes. Air entering the boxes was bubbled through water to maintain a high RH (98-100\%). At specific sampling days $(0,2,4,7,10,14$ and 21), four rachises per each $13 \mathrm{~L}$ storage box $(\mathrm{n}=3)$ were selected at random, weighed and placed inside separate $3 \mathrm{~L}$ jars at room temperature (RT) for discrete respiration measurements. Samples were equilibrated for 1 hour at RT before analysis. Each sample jar was analysed by 'push mode' for 2 min (to ensure a stable reading had been achieved) with one minute baseline measurement before and after each sample reading.

\section{Continuous respiration rate measurements}

Real-time respiration rate of fresh black pepper was measured directly from air exiting the 13 L storage boxes (at a flow of ca. $0.7 \mathrm{~L} \mathrm{~min}^{-1}$ ). Each box had an inlet and outlet bulk head connector positioned at either end of each box to which Thermo Scientific Nalgene 180 PVC tubing (3 mm internal x $5 \mathrm{~mm}$ external diameter; Thermo Fisher Scientific Corporation, MA, USA) was attached. Boxes were measured for $2 \mathrm{~min}$ with a $1 \mathrm{~min}$ baseline in between samples. The weight of samples inside each $13 \mathrm{~L}$ box was recorded every other day and this value was used for respiration rate calculations at the end of the experiment.

Avocado fruit $(\mathrm{n}=20)$ were placed into $12 \mathrm{~L}$ Lock \& Lock polypropylene containers (L\&L Nordic OÜ, Estonia) (315 x $230 \times 230 \mathrm{~mm}$ ) with freshness tray (raised platform with perforations). 
The fruit were held at $20^{\circ} \mathrm{C}$ for seven days under air or CA conditions $\left(10 \mathrm{kPa} \mathrm{CO}_{2}\right.$ and $\left.10 \mathrm{kPa} \mathrm{O}_{2}\right)$ which were controlled and maintained by a CA control system (ICA 6000). Four storage containers were connected via PVC tubing to one channel of the ICA system; this channel was split into four, providing a continuous flow ( $400 \mathrm{~mL} \mathrm{~min}^{-1}$ ) to 3 replicate boxes and one baseline box (empty). The exiting flow was passed directly to the Sable Respirometry System and respiration rate recorded continuously for seven days. Sample weight was recorded on days zero, two, four and seven, and used for further respiration rate calculations.

To accurately determine baseline values, one empty box (not filled with produce) was assigned per gaseous environment (viz. air [control] vs. CA) and subsequently subtracted from each sample reading to accurately determine $\mathrm{CO}_{2}$ production and $\mathrm{O}_{2}$ consumption. Due to the lag phase (between sample switching and sable recording), and extreme differences in gas composition between air and CA treatment $\left(10 \mathrm{kPa} \mathrm{O}_{2}\right.$ and $10 \mathrm{kPa} \mathrm{CO}$ ), baseline boxes were sampled for three consecutive intervals of 2 min prior to measuring a different CA box. This allowed the detectors to fully equilibrate to each gaseous environment before measuring the sample boxes. For replicates (sample boxes) within treatments, only a baseline interval $(2 \mathrm{~min})$ was required to eliminate cross contamination between samples. Sample boxes were measured for $2 \mathrm{~min}$.

\section{RESULTS}

\section{Discrete respiration rate measurements}

For fresh black pepper, respiration rate at RT was found to range between ca. 10 to $60 \mathrm{~mL} \mathrm{kg-1}$ $\mathrm{h}^{-1}$ (Fig. 1b). A climacteric-like peak in respiration was observed for pepper cv. Sri Lanka at the beginning of storage. However, this appeared to have started prior to starting the measurements possibly due to the delay in receiving the pepper, since harvest to arrival at CU took seven days. Respiration values were initially recorded at ca. $40 \mathrm{~mL} \mathrm{~kg}^{-1} \mathrm{~h}^{-1}$ before increasing to $50 \mathrm{~mL} \mathrm{~kg}^{-1} \mathrm{~h}^{-1}$ then decreasing to levels $<10 \mathrm{~mL} \mathrm{~kg}^{-1} \mathrm{~h}^{-1}$.
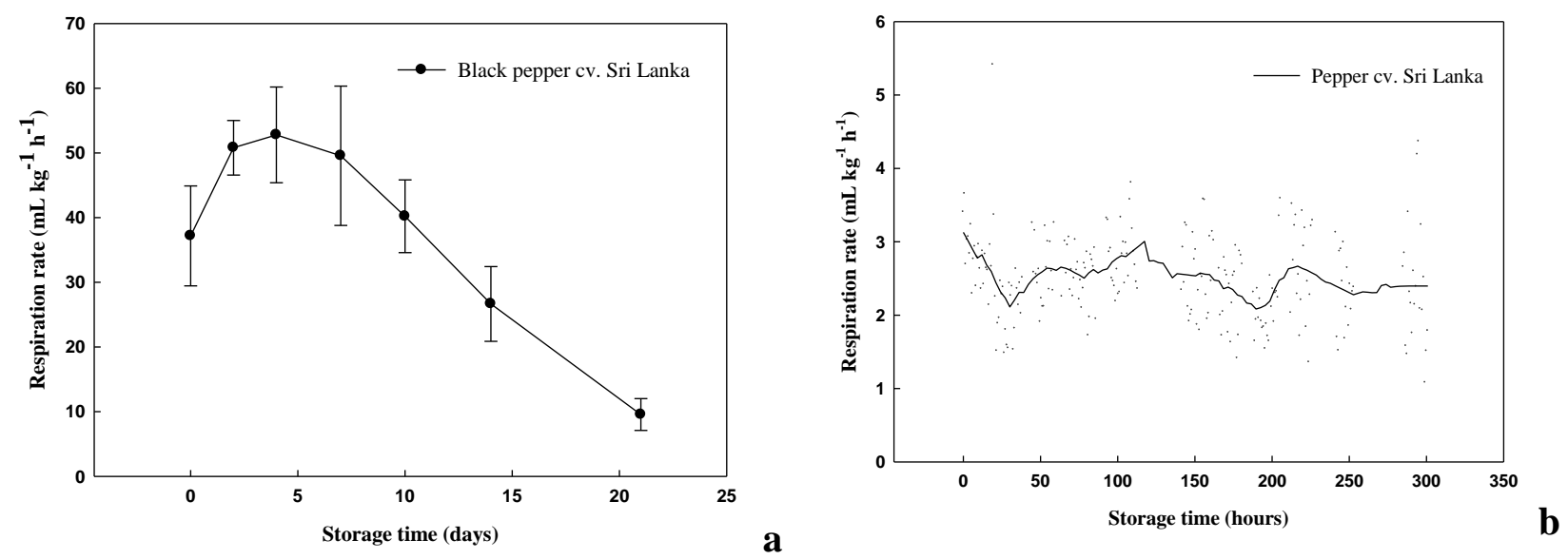

Fig. 1. Respiration rate, as $\mathrm{CO}_{2}$ production $\left(\mathrm{mL} \mathrm{kg}^{-1} \mathrm{~h}^{-1}\right)$, measured on fresh green (black) pepper cv. Sri Lanka during (A) discrete ex situ analysis performed at $23^{\circ} \mathrm{C}$ for 21 days and (B) continuous in situ analysis performed at $5^{\circ} \mathrm{C}$ for 300 hours (dots represent raw data points; lines represent smooth fit curves). Standard error (S.E.) displayed for each data point (average of 3 values) has been reported for graph A only.

\section{Continuous respiration rate measurements}

During continuous real-time measurements at $5^{\circ} \mathrm{C}$, respiration rate of fresh black (green) pepper remained constant with values ranging between 2 and $3 \mathrm{~mL} \mathrm{~kg}^{-1} \mathrm{~h}^{-1}$ (Fig. 1b). For avocado cv. 
Hass, carbon dioxide production at $20^{\circ} \mathrm{C}$ was found to range between 35 to $65 \mathrm{~mL} \mathrm{~kg}^{-1} \mathrm{~h}^{-1}$ (Figure 2), with a climacteric peak observed after $20 \mathrm{~h}$. Values for $\mathrm{O}_{2}$ consumption were 2 -fold lower compared to $\mathrm{CO}_{2}$ production with values ranging between ca. 20 to $40 \mathrm{~mL} \mathrm{~kg}^{-1} \mathrm{~h}^{-1}$, with no climacteric peak observed. The RQ value for avocado stored in air was found to increase from 1.0 to 2.0 during the seven days storage (Fig. 3). In contrast, respiration rate of avocado maintained under CA $\left(10 \mathrm{kPa} \mathrm{O}_{2}\right.$ and $10 \mathrm{kPa} \mathrm{CO}_{2}$ ) was found to remain constant with $\mathrm{CO}_{2}$ production and $\mathrm{O}_{2}$ consumption ranging between 30-40 mL kg-1 $\mathrm{h}^{-1}$ (Fig. 2). Consequently, the RQ values for avocado stored under CA, was found to be ca. 1.0 throughout storage (Fig. 3).

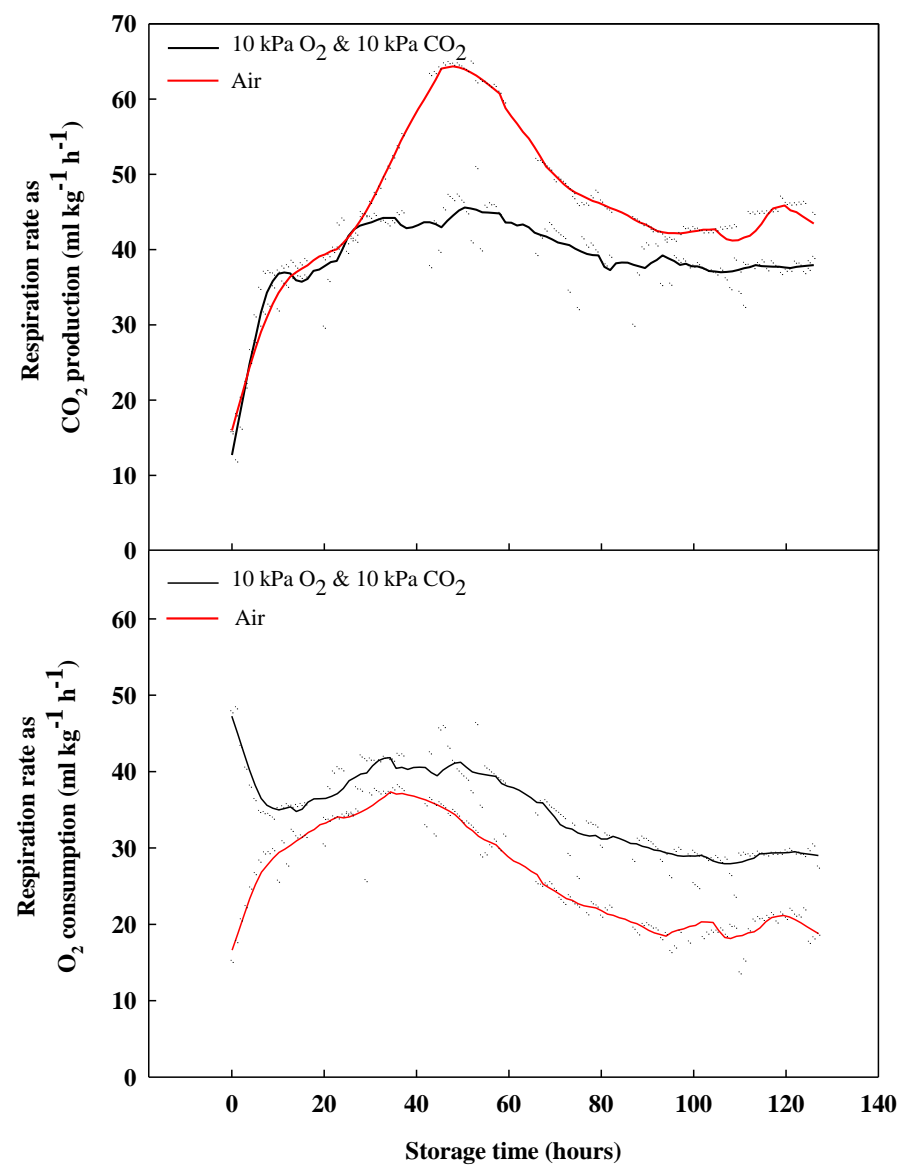

Fig. 2. Continuous real-time respiration rate as $\mathrm{CO}_{2}$ production and $\mathrm{O}_{2}$ consumption $\left(\mathrm{mL} \mathrm{kg}^{-1} \mathrm{~h}^{-1}\right)$ of avocados cv. Hass measured over seven days (126 hours) directly from the $12 \mathrm{~L}$ boxes during storage at $20^{\circ} \mathrm{C}$ under air and controlled atmosphere environment $\left(10 \mathrm{kPa} \mathrm{O}_{2}, 10 \mathrm{kPa} \mathrm{CO}_{2}\right)$ (dots represent raw data; lines represent smooth fit curves). 


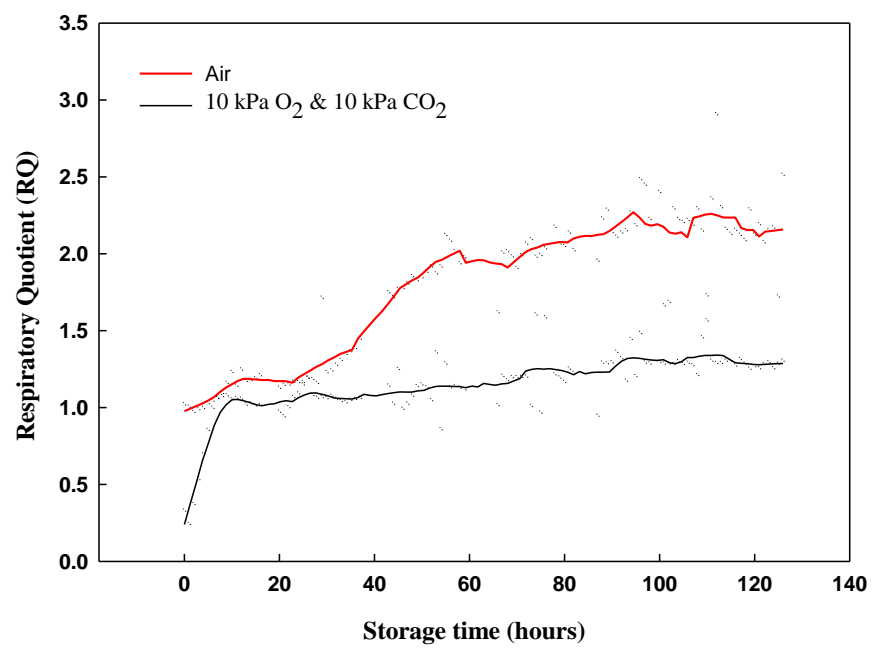

Fig. 3. Continuous respiratory quotient (RQ) values for avocado cv. Hass recorded over seven days (126 hours) during $20^{\circ} \mathrm{C}$ storage under air and controlled atmosphere environment $\left(10 \mathrm{kPa} \mathrm{O}_{2}\right.$ $10 \mathrm{kPa} \mathrm{CO}_{2}$ ). Values calculated using real-time respiration rate values as shown in Figure 2 (dots represent raw data; lines represent smooth fit curves).

\section{DISCUSSION}

\section{Determination of continuous in situ real-time respiration measurements}

To implement the continuous in situ technique, produce were placed inside storage containers with constant air flow. Additionally, this set-up ensured treatments and replicates were kept separate during storage, allowing greater control over the immediate environment surrounding the produce.

Continuous in situ respiration rate measurements $\left(\right.$ at $5^{\circ} \mathrm{C}$ ) for black pepper were found to differ from those values obtained using the discrete jar set-up (room temperature) following removal from storage. However, lower respiration rates are typically observed in produce held under cold conditions and vice versa. Therefore, the proposed automated in situ set-up would be beneficial to determine changes during storage without causing disruption to the produce. Furthermore, as produce can remain under original storage conditions, equilibration time (due to temperature change) is not required. Automated data collection during continuous measurements also allowed multiple sample boxes to be analysed simultaneously in cycles, thus providing the potential to collect large amounts of data with no disruptions / gaps over time (viz. overnight, weekends). This is useful for produce where a climacteric peak could be missed such as reported previously for black pepper (Latifah et al., 1998).

\section{Determination of continuous in situ real-time measurements under CA storage}

In addition to determining respiration under normal storage conditions, real-time respiration rate measurements using the proposed automated system can be performed on produce stored under different controlled atmosphere environments, as demonstrated for avocado. Again, this is an important innovation and has the advantage of providing an accurate assessment of metabolic rate under specific CA and storage temperatures without disturbing (viz. minimising physiology effects from handling, change in temperature and CA environment) the produce. Thus, allowing results to be more comparable to real-world scenarios. When avocados (cv. Hass) were initially placed inside the 12 $\mathrm{L}$ storage containers, an equilibration time was required prior to obtaining accurate $\mathrm{CO}_{2}$ and $\mathrm{O}_{2}$ values. However, by using the continuous method, as used herein, the exact time required to reach equilibrium was recorded and could be further discarded. Subsequent measurements thereafter did not require further equilibration due to remaining in situ. In previous work reported by Guo et al. (2013), broccoli samples required $8 \mathrm{~h}$ equilibration at $15^{\circ} \mathrm{C}$ after removal from a CA environment prior 
to discrete ex situ respiration rate measurements. Thus, in situ respiration rate analysis of fresh produce stored under CA conditions can be time and cost effective.

\section{Determination of $\mathrm{RQ}$ using simultaneous recording of $\mathrm{CO}_{2}$ and $\mathrm{O}_{2}$}

Simultaneous determination of $\mathrm{CO}_{2}$ production and $\mathrm{O}_{2}$ consumption can provide useful information on the metabolic state of fruit held under various $\mathrm{CA}$ conditions. From the results obtained for avocado stored under two environments (control [air] and CA [10 $\mathrm{kPa} \mathrm{O}_{2}, 10 \mathrm{kPa} \mathrm{CO}$ ]), it could be possible that two different types of substrates were used for respiration. Under normal conditions, typical values for RQ range between 0.97 - 1.17 suggesting oxidative respiration of carbohydrates (Hans and Schopfer, 2012). However, $\mathrm{O}_{2}$ deficit conditions and anaerobic respiration (fermentation of sugar) may have occurred in avocado stored under air resulting in the higher RQ value (1.7). This may have been due to a combination of high respiring cells (indicated by a climacteric peak in $\mathrm{CO}_{2}$ production) and reduced permeation of $\mathrm{O}_{2}$ through the thick avocado skin. Methods for accurately determining $\mathrm{O}_{2}$ and $\mathrm{CO}_{2}$ simultaneously during storage are thus, useful tools for postharvest research, particularly during CA environments.

\section{CONCLUSION}

The proposed automated continuous flow set-up generated real-time respiration rate values for various fresh produce (viz. pepper and avocado) using both discrete and continuous methods. Automated data collection generated large quantities of data without interruption from multiple samples. Simultaneous collection of $\mathrm{CO}_{2}$ and $\mathrm{O}_{2}$ also provided an accurate determination of RQ, thus, providing valuable information on metabolic state in a laboratory setting. The dynamic set-up avoided produce exposure to a modified atmosphere and also provided the opportunity to measure produce in situ under different storage conditions and, most importantly, under modified atmosphere environments. Overall, the proposed automated real-time respiration set-up appears to be a powerful technique for measuring real-time respiration rate in a variety of fresh produce.

\section{ACKNOWLEDGEMENTS}

This work was funded by the Biotechnology and Biological Sciences Research Council (BBSRC) and Johnson Matthey plc. Special thanks are also given to Nettra Somboonkaew for supplying the pepper corns used in this project.

\section{Literature cited}

Barrios, S., Lema, P. and Lareo, C. (2014). Modelling Respiration Rate of Strawberry (cv. San Andreas) for Modified Atmosphere Packaging Design. Int. J. Food Prop, 17, 2039-2051.

Calegario, F. F., Cosso, R. G., Almeida, F. V., Vercesi, A. E. and Jardin, W. F. (2001). Determination of the respiration rate of tomato fruit using flow analysis. Postharvest Biol. Technol, 22, 249-256.

Collings, E., García Cas, J.A., Ortiz, J.O., Terry, L.A., 2013. A new real-time automated method for measuring in situ respiration rates of fresh produce. Acta Hortic. (ISHS) 1012, 1151-1157.

Fonseca, S. C., Oliveira, F. A. R. and Brecht, J. K. (2002). Modelling respiration rate of fresh fruits and vegetables for modified atmosphere packages: a review. J. Food Eng, 52, 99-119.

Frateschi,C.S., Durigan, J.F., Marques, M.O., Hojo, E.T.D., Santos, L.O., Junior, L.C. and Teixeira, G.D.A. (2013). Storage of sugarcane stalks (Saccharum officinarum cv. SP 79-1011) in low oxygen atmospheres and the effects on enzymatic browning. Postharvest. Biol. Technol., 86, 154-158.

Gapper, N.E., Bai, J. and Whitaker, B.D. (2006). Inhibition of ethylene-induced $\alpha$-farnesene synthase gene PcAFS1 expression in d'Anjou pears with 1-MCP reduces synthesis and oxidation of $\alpha$-farnesene and delays development of superficial scald. Postharvest Biol. Technol., 41, 225-233.

Goyette, B., Vigneault, C., Raghavan, V., Charles, M-T. (2012). Hyperbaric treatment on respiration rate and respiratory quotient of tomato. Food Bioprocess Technol. 5:3066-3074.

Guo, Y., Gao, Z., Li, L., Wang, Y., Zhao, H., Hu, M., Li, M. and Zhang, Z. (2013). Effect of controlled atmospheres with varying $\mathrm{O}_{2} / \mathrm{CO}_{2}$ levels on the postharvest senescence and quality of broccoli (Brassica oleracea L. var. italica) florets. Eur. Food Res. Technol., 237, 943-950. 
Latifah, M. N., Shukor, A. R. A., Sim, S. I. and Bakar, A. (1998). Climacteric pattern of respiration in pepper (Piper nigrum L.). J. Trop. Agric. Food Sci, 26, 135-141.

Lighton, J.R.B. and Schilman, P.E. (2007). Oxygen Reperfusion Damage in an Insect. PLoS one, 2, e1267.

Liplap, P., Boutin, J., LeBlanc, D.I., Vigneault, C. and Raghavan, G.S.V. (2014). Effect of hyperbaric pressure and temperature on respiration rates and quality attributes of Boston lettuce. Int. J. Food Sci. Technol, 49, 137-145.

Mahajan, P. V., Luca, A. and Edelenbos, M. (2016). Development of a small and flexible sensor-based respirometer for realtime determination of respiration rate, respiratory quotient and low 02 limit of fresh produce. Comput. Electron. Agric. 121, 347-353.

Melanson, E.L., Ingebrigsten, J.P., Bergouignan, A., Ohkawara, K., Kohort, W.M. and Lighton, R.B. (2012). A new approach for flow-through respirometry measurements in humans. Amer. J. Physiol. - Regul. Integr. Comp. Physiol. 298, 1571-1579.

Saquet, A.A., Streif, J. and Bangerth, F. (2003). Energy metabolism and membrane lipid alterations in relation to brown heart development in Conference pears during delayed controlled atmosphere storage. Postharvest Biol. Technol. 30, 123-132.

Watada, A. E. and Massie, D. R. (1981). A compact automatic system for measuring $\mathrm{CO}_{2}$ and $\mathrm{C}_{2} \mathrm{H}_{2}$ evolution by harvested crops. HortScience. 16, 39-41. 